\title{
BMJ Open Positive impact of the COVID-19 pandemic? A longitudinal study on the impact of the COVID-19 pandemic on physicians' work experiences and employability
}

Evelien H van Leeuwen (D) , ${ }^{1,2}$ Toon Taris, ${ }^{3}$ Elizabeth L J van Rensen, ${ }^{1}$ Eva Knies, ${ }^{2}$ Jan-Willem Lammers ${ }^{4}$

To cite: Leeuwen EH, Taris T, van Rensen ELJ, et al. Positive impact of the COVID-19 pandemic? A longitudinal study on the impact of the COVID-19 pandemic on physicians' work experiences and employability. BMJ Open 2021;11:e050962. doi:10.1136/ bmjopen-2021-050962

- Prepublication history for this paper is available online. To view these files, please visit the journal online (http://dx.doi. org/10.1136/bmjopen-2021050962).

Received 07 March 2021 Accepted 28 0ctober 2021

Check for updates

(c) Author(s) (or their employer(s)) 2021. Re-use permitted under CC BY-NC. No commercial re-use. See rights and permissions. Published by BMJ.

${ }^{1}$ Department of Quality and Patient Safety, UMC Utrecht, Utrecht, The Netherlands ${ }^{2}$ Department of Strategic Human Resource Management, Utrecht University School of Governance, Utrecht, The Netherlands ${ }^{3}$ Department of Social, Health and Organizational Psychology, Utrecht University, Utrecht, The Netherlands

${ }^{4}$ Department of Respiratory Medicine, UMC Utrecht, Utrecht, The Netherlands

Correspondence to

Evelien $\mathrm{H}$ van Leeuwen;

e.h.vanleeuwen@umcutrecht.nl

\section{ABSTRACT}

Objective The COVID-19 pandemic places an enormous demand on physicians around the world. The aim of this study was to examine the impact of the COVID-19 pandemic on physicians' work experiences and their ability and willingness to continue working in their profession until retirement (ie, their employability).

Design A longitudinal comparative design was used. Survey data were collected on three moments: before (May 2019), in the early phase (May 2020) and in a later phase (November 2020) of the COVID-19 pandemic. Time effects were tested using repeated-measures analyses of variance and one-way analyses of variance.

Setting This study took place among physicians of two hospitals in a large city in the Netherlands.

Participants 165 hospital physicians with surgical, medical and other specialties participated in this study. Results Physicians' employability significantly increased from the time prior to the COVID-19 pandemic, compared with the period during this pandemic. Employability differs among physicians with surgical, medical and other specialties. Furthermore, physicians experienced a lower emotional, physical and quantitative workload during the first peak of the COVID-19 pandemic, compared with before the pandemic. Moreover, physicians experienced the most stress from the impact of COVID-19 on their work in general and from combining work and private life. Conclusions This study shows that physicians' employability and work experiences are affected by the COVID-19 pandemic. Work experiences vary for physicians with different specialties. These varieties stress the importance of attention for physicians' individual needs and challenges regarding working during the COVID-19 pandemic and the possibility of continuing work in the aftermath of this crisis. Based on this, physicians can be offered tailor-made solutions. This is important to maintain a healthy and employable workforce, which is essential for a sustainable healthcare system.

\section{INTRODUCTION}

Healthcare workers stand in the frontline of healthcare pandemics. ${ }^{1}$ They are highly vulnerable during these pandemics, given
Strengths and limitations of this study

- The study captured the work experiences of physicians prior to and during the COVID-19 pandemic, allowing for within-person comparisons.

- The study used a longitudinal study approach with data collected at three moments in time.

- Despite the highly relevant longitudinal study approach, this has also resulted in participants dropout.

the risk of exposure to the virus, concerns about infecting their loved ones, shortages of personal protective equipment, extended workload and involvement in emotional and ethical decision making. ${ }^{2-4}$ The COVID-19 pandemic is likely to have implications for healthcare workers' ability and willingness to work in the short run and to continue their essential work on the frontlines in the long run. ${ }^{5}$ Evidence from earlier studies on the impact of the COVID-19 pandemic on healthcare workers, including metaanalyses and systematic reviews, show that the COVID-19 pandemic results in stress, ${ }^{6}$ illness, insomnia, ${ }^{17}$ fear for becoming infected, ${ }^{8}$ hesitation to work $^{9}$ or a lack of motivation to work $^{10}$ in the short run. From previous research on crises, we know that a pandemic may even result in more adverse consequences for physicians in the long run, such as developing burn-out, psychological distress and post-traumatic stress disorder. ${ }^{11} 12$

The possible consequences of crises for physicians make it important to monitor physicians' work experiences (ie, their perceived workload, job autonomy and stress) and their ability and willingness to continue working in their profession (ie, employability). It is important to prevent adverse consequences, because healthcare 
workers' well-being might be at stake. Studying physicians' work experiences helps to monitor their ability to work in the short term. Especially job demands (such as workload) and job resources (such as job autonomy) have been shown to be important factors that affect well-being, stress and performance. ${ }^{13-15}$ Furthermore, employability provides an indication of physicians' ability and willingness to continue working in their profession. Research has shown that employability positively affects well-being and performance. ${ }^{16}{ }^{17}$ Research has shown that crises, such as the COVID-19 pandemic, are so-called 'career shocks' referring to disruptive and extraordinary events caused by factors outside an individual's control, triggering a deliberate thought process concerning ones' career. ${ }^{18}$ This may result in people reconsidering their position, leaving their profession or lower job or career satisfaction. ${ }^{19}$ This challenges their employability, which is especially problematic in a health crisis as employable physicians are needed to handle the high demands for healthcare and in the aftermath of the health crisis due to delayed operations and other treatments for instance.

In this study, we examine the impact of the COVID-19 pandemic on physicians' work experiences and employability, by addressing the following research question in the context of a three-wave prospective study: 'What is the impact of the COVID-19 pandemic on physicians' work experiences (ie, perceived workload, job autonomy and stress) and their ability and willingness to continue working in their profession (ie, employability)?'. Understanding the impact of the COVID-19 pandemic on physicians' work is important to be prepared for future outbreaks of health crises, as maintaining a healthy and employable workforce is essential for a sustainable healthcare system. These themes, and topics related to this, have to date received little attention, especially in a medical setting. Physicians tend to self-ignore attention for their well-being and health systems poorly support this,${ }^{20}$ emphasising the importance of this research.

This study examines the impact of the COVID-19 pandemic on physicians with varying specialties. Previous studies have found mixed outcomes for the impact of the COVID-19 pandemic on healthcare workers working in different departments. ${ }^{21-23}{ }^{22} 23$ For instance, one study found that those who work in emergency departments, intensive care units and isolation wards have a greater risk of developing adverse psychiatric outcomes than those working in other departments. ${ }^{22}$ Another study found the opposite, physicians and nurses who worked in the frontline had a lower frequency of burn-out and were less worried about being infected with the COVID-19 virus compared with those working in usual wards. ${ }^{23}$ Yet another study found no differences in mental health outcomes for physicians and nurses working in COVID-19 care units, non-COVID-19 care units or in both units. ${ }^{24}$ Despite possible differences between physicians working in different departments, it is likely that pandemics, such as the COVID-19 pandemic, affects them all to some extent as their work has suddenly changed, both in terms of content (eg, change in cases and increase in the use of video consults) and location (eg, working from home or in different departments) and due to an uncertain future. These changes may result in various job demands such as a high (emotional) workload or stress, ${ }^{125}$ which may vary between groups of physicians. More research is needed to understand the impact of pandemics on physicians with different specialties. This study examines physicians with surgical, medical and other specialties to examine the impact on their work and possible differences between specialties.

Studies examining the psychological effects of pandemics (eg, SARS, H1N1 influenza and avian influenza H5N1), including recent studies into the COVID-19 pandemic, often use cross-sectional methods. ${ }^{70-12} 26$ A disadvantage of this approach is that it cannot capture the dynamics of pandemics. The impact of pandemics on healthcare workers has been shown to vary in different phases of the pandemic. During the initial outbreak, healthcare workers perceive feelings of extreme vulnerability, uncertainty, anxiety and threat, while mental health problems such as depression are more likely to develop in a later phase. ${ }^{27}$ For this reason, a longitudinal approach where experiences are measured at multiple points in time is more appropriate to study the impact of a pandemic. In this study we use a longitudinal approach by examining physicians experiences at three moments in time.

In addition, a meta-analysis shows that these studies often use retrospective questions where respondents are asked for their past experiences. ${ }^{28}$ This approach is problematic as psychologists and survey methodologists have shown that subjective experiences are poorly represented in memory. Retrospective questions often ask respondents for information that they cannot provide with any validity. ${ }^{29}$ Therefore, examining behaviour and experiences by using real-time data is highly preferable. ${ }^{29}$ This is done in this study by asking for physicians' current behaviour at the three moments of taking the surveys.

Based on prior studies into the impact of health crises on healthcare workers, together with early evidence on the impact of the COVID-19 pandemic on healthcare workers, we expect that physicians experience their work more negatively during the COVID-19 pandemic compared with the situation prior to this pandemic, which will be reflected in a higher emotional, physical and quantitative workload. Furthermore, we expect that physicians are more negative about their employability during the pandemic, compared with the situation prior to the COVID-19 pandemic, and have a lower job and career satisfaction during the pandemic compared with the time prior to the pandemic.

\section{METHOD}

Three surveys were sent to physicians in two hospitals in a large Dutch city, an academic hospital and a general hospital. The first survey was sent as part of another study. ${ }^{30}$ The sample size of this study was therefore predetermined by the sample of the prior study that was calculated according to a power analysis. The first survey was sent in May 2019 (T1), prior to the COVID-19 outbreak. 


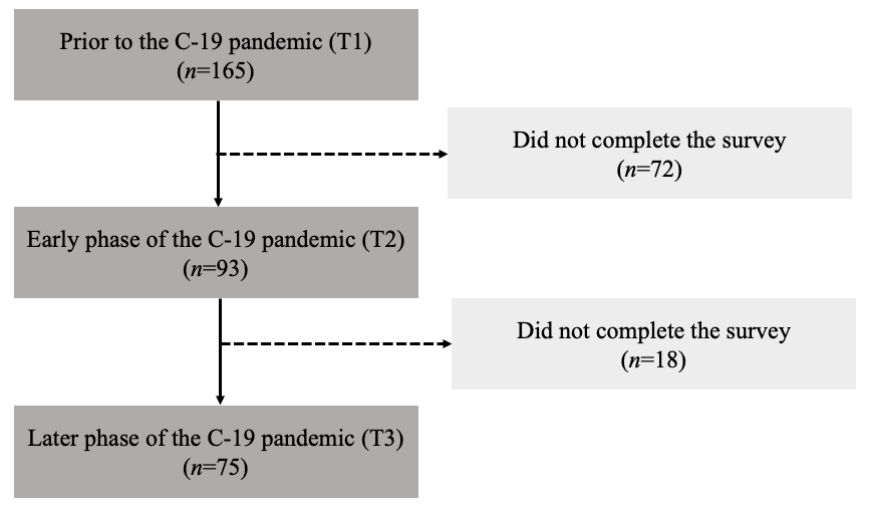

Figure 1 Flow chart of participants at T1, T2 and T3.

A second survey was sent in May 2020, in an early phase of the COVID-19 pandemic. This was 1 month after the first peak of COVID-19 infections in the Netherlands. ${ }^{31}$ At this time, both hospitals had established a COVID-19 clinic and an COVID-19 intensive care unit, which were separated from other departments in the hospital. Furthermore, in both hospitals, non-emergent care and surgeries were postponed. Physicians and healthcare workers from different departments were requested to support on the COVID-19 departments. Healthcare professionals were supported with volunteers from 'outside' who were not employed by the hospitals. The long period in which the COVID-19 pandemic dominates the world made it relevant to add a study wave in a later phase of the pandemic to examine its longer term consequences. Therefore, a third survey was sent in November 2020 (T3), 1 month after the second peak of COVID-19 in the Netherlands. During the first and second peak of the number of COVID-19 infections, there were 60 patients infected with the COVID-19 virus in the academic hospital (20 on the intensive care and 40 in the COVID-19 clinic) and 30 in the general hospital (eight on the intensive care and 22 in the COVID-19 clinic). When the surveys were sent at T2 and T3, many countries, including the Netherlands, were partly or fully in lockdown, social distancing was required and the number of patients infected with COVID-19 was high. In the two hospitals where this study took place, waiting lists for patients were higher at T3 than at T2 due to non-emergent care that was still being postponed.

Participants were recruited through promotional presentations and through an internal mailing list. Participants provided informed consent at the start of each survey stating that participation is voluntary, outcomes are held confidential, participants can withdraw from the study at any time and all study material was anonymised and saved on a protected server. One hundred and sixty-five physicians participated in this study at T1. These 165 physicians were invited by e-mail to complete a second and a third survey. Ninetythree physicians completed the survey at T2 (response rate: $56 \%$ ), and 75 physicians completed all three surveys (response rate: $45 \%$ ). A flow chart of the participants in this study is presented in figure 1 . We compared participants who completed all three surveys (T1, T2 and T3) $(\mathrm{n}=75)$ with participants who only completed the survey sent at T1 $(n=72)$. Multivariate analysis of variance indicated that there were no significant differences between these participants in terms of age $(F(1,124)=0.037, \mathrm{p}=0.849)$, hours worked according to contract $(F(1,135)=0.555, \mathrm{p}=0.458)$, occupational tenure $(F(1,133)=0.591, \mathrm{p}=0.443)$ and organisational tenure $(F(1,129)=0.804, \mathrm{p}=0.371)$. For the dichotomous variables gender, hospital type (general vs academic), type of specialism (surgical, medical vs other, following the categorisation of ref $^{32}$ ) and type of employment contract (employed by the hospital vs independently established), we conducted $\chi^{2}$ tests, again showing that there were no significant differences between participants who dropped out of this study and the participants who completed all three surveys (all ps $>0.452$ ).

Physicians provided several reasons for not completing the surveys sent at T2 and/or T3. At T2, 1 physician had left the hospital, and 10 physicians were on leave (either a pregnancy leave, holiday leave or were abroad). At T3, 2 physicians had left the hospital, 10 physicians were on leave and 1 physician was 'too busy' to complete the survey. These reasons, apart from the latter, are unlikely to result in biased outcomes. This, together with the non-significant results for the non-response analysis, show that there are no significant differences between the participants who dropped out of this study and the participants who completed all three surveys. The result section reports on the results of the analyses based on the data from participants who completed the surveys on $\mathrm{T} 1, \mathrm{~T} 2$ and T3 $(\mathrm{n}=75)$.

The questions addressed sociodemographic characteristics (gender and age), job characteristics (specialism, autonomy, workload, occupational tenure referring to the time working as a medical specialist and organisational tenure referring to the time working in their current hospital) and involvement with care for patients with the COVID-19 virus. Most variables were measured with validated scales, if available. Work characteristics were measured using validated scales from the popular surveys: 'VBBA 2.0,33 and the Work Design Questionnaire. ${ }^{34}$ Physicians were asked to rate their emotional workload (five items: 'Is your job emotionally demanding?, 'Are you confronted in your work with things that affect you personally?', 'Are you in your work in contact with difficult patients or their relatives?', 'Do you have to convince or persuade people for your job?' and 'Do you encounter emotionally demanding events in your work?', $\alpha_{\mathrm{T} 1}=0.96 ; \alpha_{\mathrm{T} 2}=0.82 ; \alpha_{\mathrm{T} 3}=0.82,{ }^{33}$ ), quantitative workload (three items: 'Do you have too much work to do?', 'Do you have to put in extra effort to finish your work?' and 'Do you have to hurry?', $\alpha_{\mathrm{T} 1}=0.90 ; \alpha_{\mathrm{T} 2}=0.91 ; \alpha_{\mathrm{T} 3}=0.93,{ }^{33}$ ), physical workload (one item: 'My job is physically demanding, ${ }^{35}$ ) and job autonomy (three items: 'The job allows me to decide on my own how to go about doing my work', 'The job provides me with significant autonomy in making decisions' and 'The job gives me a chance to use my personal initiative or judgment in carrying out the work', $\left.\alpha_{\mathrm{T} 1}=0.80 ; \alpha_{\mathrm{T} 2}=0.72 ; \alpha_{\mathrm{T} 3}=0.79^{34}\right)$. Answers were given on a 5 -point Likert scale ( $1=$ never, $5=$ very often).

Other questions asked for physicians' perceptions of their own employability (two items measured ability: ' $I$ am [physically (item 1)/ mentally (item 2)] able to continue 
to work until the age of 67 in my current profession'; one item measured willingness: 'I am willing to continue to work until the age of 67 in my current profession ${ }^{36}$ ). This is a common way to measure employability, which is also used in a big survey research among employees in the Netherlands called the NEA (abbreviation for 'Nederlandse Enquête Arbeidsomstandigheden', translation: Dutch Survey on Work conditions). Job satisfaction and career satisfaction were both measured with one item ('Generally speaking, I am very satisfied with my job ${ }^{37}$ and 'Generally speaking, I am very satisfied with my career $^{38}$ ). Previous studies have shown that a single item measure of job satisfaction is appropriate especially when situational constraints limit or prevent the use of scales. ${ }^{37}$ Answers were given on a 5-point Likert scale (1=totally disagree, $5=$ totally agree).

The surveys sent on T2 and T3 additionally asked for perceived stress associated with the Covid-19 situation. This was measured with items that are relevant for employees working during the Covid-19 pandemic. Some specifically related to the work of healthcare workers as they may experience stress due to the health of their patients or colleagues who have a higher risk of infection (10 newly developed items: 'How often do you experience stress caused by Covid-19 [for work (item 1)/ about the measures taken against Covid-19 (item 2)/ for your work-life balance (item 3)/ messages in the media (item 4)/ yourself (item 5)/ love ones (item 6)/ your patients (item 7)/ your colleagues (item 8) / the hospital where you work (item 9) / the profession of physicians (item 10) ]', that were all rated on a 5 -point Likert scale ( $1=$ never, 5 =very often $)$ ).

\section{Patient and public involvement}

This study was conducted among physicians; patients were not involved in this study. Physicians were involved in developing the surveys that were used in this study. The survey was pilot tested among five physicians. They were interviewed about the content, wording and style of addressing physicians in the survey. If needed, the content and the item wordings were adapted. Furthermore, the researchers of this study developed the surveys and interpreted results with the support of a senior board member and two physicians-one from the academic and one from the general hospital. The outcomes of this study are discussed in both hospitals in a group of representative physicians from all departments.

\section{Data analysis}

To examine physicians' employability, a repeated measures analyses of variance (RM ANOVA) was performed with planned contrasts on time (Helmert contrasts T1 vs T2/ T3) and with time as a within-subject factor and group as a between-subject factor.

Furthermore, one-way ANOVAs were performed to compare groups (physicians with surgical, medical or another specialty) and work experiences over time (T1, T2 and T3).
Table 1 Demographics of participants $(n=75)$

\begin{tabular}{|c|c|}
\hline Gender & $\begin{array}{l}\text { Male: } \mathrm{n}=28(37 \%) \\
\text { Female: } \mathrm{n}=47(63 \%)\end{array}$ \\
\hline Age & $M=44.9, S D=7.8$ \\
\hline $\begin{array}{l}\text { Work hours } \\
\text { according to } \\
\text { contract }\end{array}$ & $M=41.4, S D=11.12$ \\
\hline $\begin{array}{l}\text { Occupational } \\
\text { tenure (years) }\end{array}$ & $M=11.6, S D=8.4$ \\
\hline $\begin{array}{l}\text { Organisational } \\
\text { tenure (years) }\end{array}$ & $M=9.6, S D=8.0$ \\
\hline $\begin{array}{l}\text { Type of } \\
\text { employment } \\
\text { contract }\end{array}$ & $\begin{array}{l}\text { Self-employed: } n=10(13 \%) \\
\text { Contracted: } n=65(87 \%)\end{array}$ \\
\hline Specialty & $\begin{array}{l}\text { Surgical: } n=14(19 \%) \\
\text { Medical: } n=35(47 \%) \\
\text { Other: } n=26(35 \%)\end{array}$ \\
\hline $\begin{array}{l}\text { Involved in care for } \\
\text { COVID-19 patients } \\
\text { at T2 }\end{array}$ & $\begin{array}{l}\text { Yes: } n=24(32 \%) \text {, of which } n=6(25 \%) \text { had a } \\
\text { surgical specialty, } n=13(54 \%) \text { had a medical } \\
\text { specialty and } n=5(21 \%) \text { had another specialty } \\
\text { No: } n=51(68 \%)\end{array}$ \\
\hline $\begin{array}{l}\text { Involved in care for } \\
\text { COVID-19 patients } \\
\text { at T3 }\end{array}$ & $\begin{array}{l}\text { Yes: } n=19(25 \%) \text {, of which } n=4(21 \%) \text { had a } \\
\text { surgical specialty, } n=10(53 \%) \text { had a medical } \\
\text { specialty and } n=5(26 \%) \text { had another specialty } \\
\text { No: } n=56(75 \%)\end{array}$ \\
\hline
\end{tabular}

\section{RESULTS}

Table 1 presents the demographics of the respondents.

\section{Employability is higher during the COVID-19 pandemic than before}

RM ANOVAs show that physicians' perceived employability significantly increased over time (figure 2). Specifically, physicians' mental and physical ability to work and to continue working in their current profession significantly increased from the time before the COVID-19 pandemic (T1) compared with the period during the COVID-19 pandemic (T2 and T3) $\left(F(1,67)=4.954, \mathrm{p}=0.029^{*}\right.$, partial $\eta^{2}=0.069$ ). Similarly, physicians' willingness to work and to continue to work significantly increases from the time before the pandemic compared with the period during the pandemic $\left(F(1,65)=11.125\right.$, $\mathrm{p}=0.001^{* *}$, partial $\left.\eta^{2}=0.146\right)$.

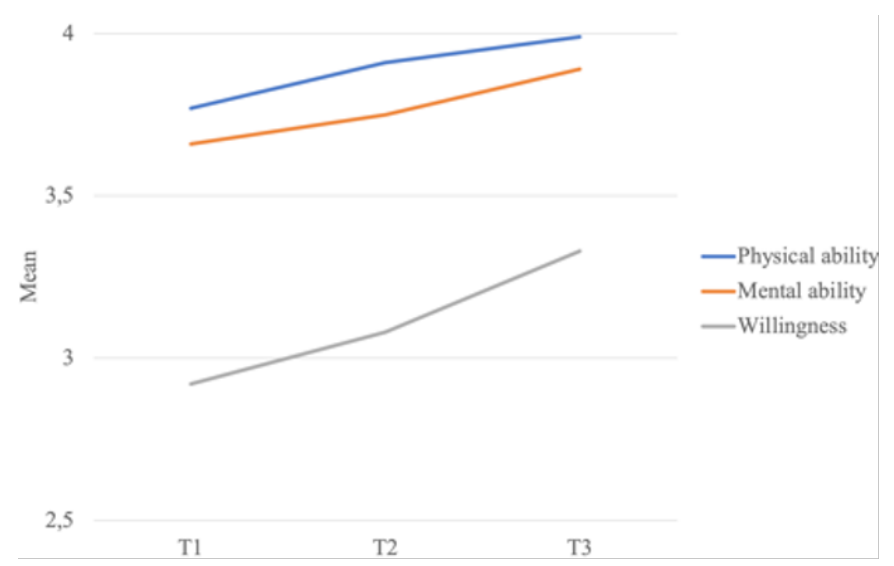

Figure 2 Mean scores for employability on T1, T2 and T3. 

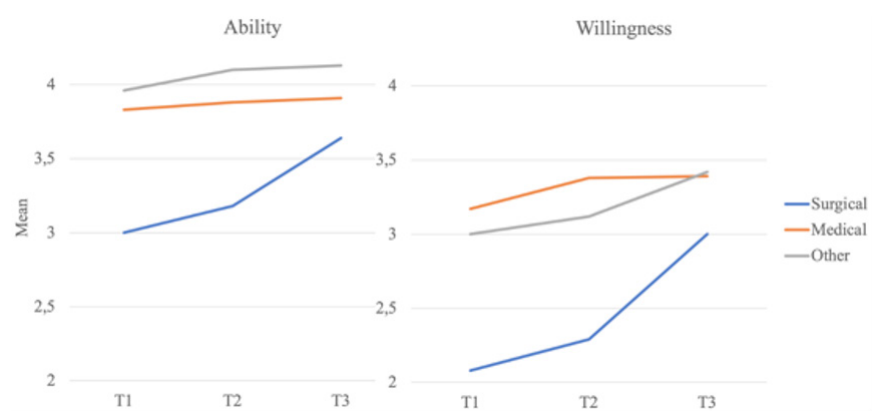

Figure 3 Mean scores for employability on T1, T2 and T3 for physicians with surgical, medical and other specialties.

We observe a similar significant increase in physicians' career satisfaction from prior to the COVID-19 pandemic (T1) to during the COVID-19 pandemic (T2 and T3) $\left(F(1,72)=6.294, \mathrm{p}=0.014^{*}\right.$, partial $\left.\eta^{2}=0.080\right)$. No significant change was found for physicians' job satisfaction in this period. Moreover, no significant differences were found in the employability, job and career satisfaction for physicians who were involved in taking care for patients infected with the COVID-19 virus and physicians that were not involved in COVID-19 related care.

\section{Employability differs between specialties}

Further analyses show that employability differs among physicians with surgical, medical and other specialties (figure 3). At T1, surgical doctors are significantly less positive about their employability than physicians with medical or other specialties (ability: $F(2,71)=6.412, \mathrm{p}=0.003^{* *}$, partial $\eta^{2}=0.153$; willingness $F(2,68)=4.200, \mathrm{p}=0.019 *$, partial $\left.\eta^{2}=0.110\right)$. Furthermore, during the first phase of the COVID-19 pandemic (T2), the employability of surgical doctors is still significantly lower than that of physicians with medical or other specialties (ability: $F(2,70)=6.492$, $\mathrm{p}=0.003^{* *}$, partial $\eta^{2}=0.156$; willingness: $F(2,71)=5.941$, $\mathrm{p}=0.004^{* *}$, partial $\left.\eta^{2}=0.143\right)$. At T3, there are no significant differences anymore between the employability of the three groups of medical specialties. Table 2 summarises the differences in employability over time among physicians with surgical, medical and other specialties.
Physicians' work experiences during the COVID-19 pandemic We further examined how physicians experience their work during the COVID-19 pandemic. Table 3 shows that physicians experience a significant lower emotional workload $(F(2,70)=10.579, \mathrm{p}<0.001 * *$, physical workload $\left(F(2,72)=5.159, \quad \mathrm{p}=0.008^{* *}\right.$ and quantitative workload $\left(F(2,62)=5.702, \mathrm{p}=0.005^{* *}\right.$ during an early phase of the COVID-19 pandemic (T2) compared with the time before the pandemic (T1). In a later phase of the pandemic (T3), the experience of workload showed a tendency to return to the pre-pandemic levels (T1) (figure 4). There were no significant differences in the experiences of these work characteristics for physicians who were involved in COVID-19 related care and physicians who were not.

\section{Stress factors during the COVID-19 pandemic}

Physicians further reported to what extent they experience stress in several areas because of the COVID-19 pandemic (figure 5). During an early phase of this pandemic (T2), physicians experienced the most stress from combining work and private life $(M=2.63 ; S D=1.27)$, from work in general $(M=2.49 ; S D=0.95)$ and due to the possible impact of COVID-19 on their loved ones' health $(M=2.33$; $S D=0.93)$. They experienced the least stress for the possible consequences of COVID-19 for themselves $(M=1.85 ; S D=0.85)$. During a later phase of the COVID-19 pandemic (T3), physicians reported to experience the most stress from their work in general $(M=2.55 ; S D=1.00)$, from combining work and private life $(M=2.47 ; S D=1.12)$ and due to the health of their patients $(M=2.38 ; S D=0.98)$. Again, they reported to experience the least stress for the possible impact of COVID-19 on themselves $(M=2.03 ; S D=0.72)$.

\section{DISCUSSION}

The aim of this study was to provide insight into the impact of the COVID-19 pandemic on physicians' employability and work experiences. A longitudinal approach was used, which allowed us to compare physicians work experiences during the COVID-19 pandemic with the situation prior to the pandemic.

Table 2 Results one-way ANOVAs employability on T1, T2 and T3 for physicians with surgical, medical and other specialties $(n=75)$

\begin{tabular}{|c|c|c|c|c|c|c|c|c|c|}
\hline \multirow[b]{2}{*}{ Variable } & \multirow[b]{2}{*}{ Time } & \multicolumn{2}{|c|}{ Surgical } & \multicolumn{2}{|c|}{ Medical } & \multicolumn{2}{|c|}{ Other } & \multirow[b]{2}{*}{ F values } & \multirow[b]{2}{*}{ Partial n2 } \\
\hline & & $\mathbf{M}$ & SD & $\mathbf{M}$ & SD & $\mathbf{M}$ & SD & & \\
\hline \multirow[t]{2}{*}{ Ability to continue working } & T1 & 3.00 & 1.22 & 3.83 & 0.79 & 3.96 & 0.64 & $F(2,71)=6.412, p=0.003^{* *}$ & 0.153 \\
\hline & T3 & 3.64 & 1.08 & 3.91 & 0.96 & 4.13 & 0.71 & $F(2,69)=1.256, \mathrm{p}=0.291$ & $x$ \\
\hline \multirow[t]{2}{*}{ Willingness to continue working } & T1 & 2.08 & 1.26 & 3.17 & 1.22 & 3.00 & 1.04 & $F(2,68)=4.200, \mathrm{p}=0.019^{\star}$ & 0.110 \\
\hline & T3 & 3.00 & 1.24 & 3.39 & 1.20 & 3.42 & 1.06 & $F(2,70)=0.700, \mathrm{p}=0.500$ & $x$ \\
\hline
\end{tabular}

*Significant at the 0.05 level (two tailed) and **significant at the 0.01 level (two tailed).

ANOVAs, analyses of variance. 
Table 3 Results one-way ANOVAs experience of work characteristics on T1, T2 and T3 $(n=75)$

\begin{tabular}{|c|c|c|c|c|c|c|c|c|}
\hline \multirow[b]{2}{*}{ Work characteristics } & \multicolumn{2}{|l|}{ T1 } & \multicolumn{2}{|l|}{ T2 } & \multicolumn{2}{|l|}{ T3 } & \multirow[b]{2}{*}{ F values } & \multirow[b]{2}{*}{$\eta 2$} \\
\hline & $\mathbf{M}$ & SD & $\mathbf{M}$ & SD & M & $S D$ & & \\
\hline Emotional workload & 2.70 & 0.67 & 2.45 & 0.63 & 2.51 & 0.67 & $F(2,70)=10.579, \mathrm{p}<0.001^{\star *}$ & 0.232 \\
\hline Quantitative workload & 3.45 & 1.11 & 2.99 & 1.03 & 3.22 & 1.11 & $F(2,62)=5.702, \mathrm{p}=0.005^{\star \star}$ & 0.155 \\
\hline Job autonomy & 3.82 & 0.80 & 3.64 & 0.54 & 3.76 & 0.60 & $F(2,63)=2.417, p=0.097$ & $x$ \\
\hline
\end{tabular}

${ }^{*}$ Significant at the 0.05 level (two tailed) and ** significant at the 0.01 level (two tailed).

Perhaps the most interesting finding of the present study was the fact that the perceived employability of physicians was significantly higher during the pandemic than it was before. Specifically, the results show that physicians' employability increases in the time prior to the COVID-19 pandemic to the early phase of the COVID-19 pandemic and continues to increase in a later phase of the COVID-19 pandemic. This goes contrary to our expectations, since other studies found that physicians' work motivation decrease ${ }^{10}$ and stress and burn-out increase during previous pandemics. ${ }^{11} 12$ There are various substantive explanations for this increase in employability. It could be related to a change in physicians' work characteristics or an increase in societal appreciation of healthcare professionals during the pandemic. This study shows that physicians experienced a lower workload during an early phase of the COVID-19 pandemic compared with the time prior to the pandemic. Workload has also been shown to correlate with employability. Therefore, a lower workload at this time could possibly explain why physicians perceive to be better able to continue working until their retirement. This is in line with research showing that job demands, such as workload, negatively relate to well-being and self-reported health $\left(\mathrm{eg}, \mathrm{ref}^{15}\right)$. This suggests that having a period of lower job demands may be beneficial for an individual's well-being or related concepts such as employability. More research is needed to examine this further.

More appreciation for physicians' work by society ${ }^{9}$ may provide an alternative explanation for the increase in their employability. Physicians and other healthcare workers have been portrayed as 'heroes', ${ }^{39}$ and citizens have expressed their support through a public applause

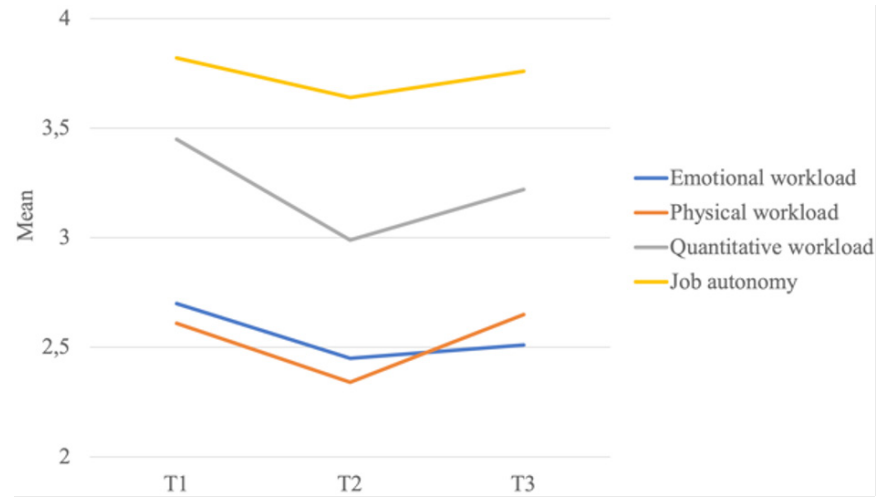

Figure 4 Mean scores for work characteristics on T1, T2 and T3. and by placing white t-shirts with red hearts in front of their windows. Physicians are on the shortlist of 'vital professions', which gives them certain privileges during the pandemic compared with people with other professions (eg, they may use public transport and their children can still go to daycare and school). This might have resulted in physicians feeling highly appreciated during the COVID-19 pandemic, which may have boosted their ability and willingness to work and to continue their essential and meaningful work.

A possible explanation for the different conclusions drawn in this study compared with other studies on the impact of previous pandemics ${ }^{10-12}$ may be the result of a different approach taken in our study compared with these past studies. Earlier studies drew conclusions on the basis of cross-sectional, retrospective data. Recall biases are inherent to studies using retrospective techniques to understand a change in experience over time. ${ }^{29}$ Studies have shown that when respondents have reason to believe in change, they will report change when they are asked to reflect on the past, even if no change has occurred. ${ }^{29}$ In a crisis situation, such as a pandemic, respondents may believe that they were more positive before the outbreak of a pandemic than during the pandemic. This perspective is likely to be strengthened by the public debate where the negative impact of the pandemic on healthcare workers has frequently been emphasised. A strength of our study is that we used real-time data collection, instead of retrospective methods. We asked physicians about things that they can report, namely their current experiences at the moment of taking the survey, that is, they reported on their current feelings, not on their perceptions of their feelings in the past. This approach allows for drawing considerably more reliable conclusions about physicians' work

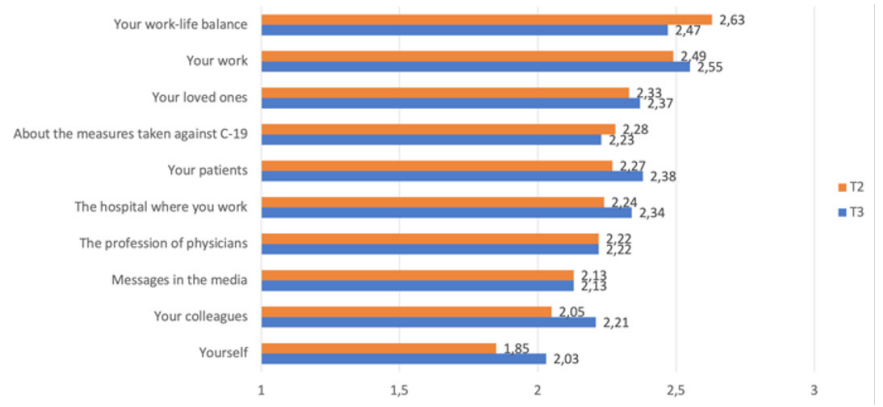

Figure 5 Mean scores on how often physicians experience stress in several areas on T2 and T3 caused by COVID-19. 
experiences prior to a pandemic and during a pandemic than is possible using non-longitudinal methodologies.

Physicians employability differed across surgical, medical and other specialties. This difference is also apparent before the COVID-19 pandemic. This is in line with previous studies showing that physicians with different specialties experience their work differently. There are for instance significant differences in job stressors, demands and resources among medical specialties. ${ }^{40}$ Another interesting finding is that the employability of physicians with surgical specialties increased stronger from the time prior to the COVID-19 pandemic to the time during the COVID-19 pandemic compared with physicians with medical or other specialties. We tested whether this difference is caused by the degree of involvement with care for patients with COVID-19, but this was not the case. Other factors might explain this difference. Physicians with different specialties had very diverse roles during the COVID-19 pandemic. While some physicians were directly involved in taking care for patients with COVID-19 or were part of crisis teams, making very long workdays, other physicians' work was significantly reduced due to postponed or cancelled non-COVID-19 related care. ${ }^{41}$ Therefore, the job demands of physicians with different specialties varied during the COVID-19 pandemic. For example, job demands for physicians with surgical specialties could be lower during the COVID-19 pandemic as they saw their work being reduced due to the cancellations of operations. This could have reduced their (physical) workload more strongly than the workload of physicians with medical or other specialties which could explain the rise in their employability.

\section{Limitations}

This study has some limitations. First, although a longitudinal approach is highly relevant to understanding the impact of a pandemic over time, the disadvantage of this approach is a high attrition rate of participants. In this study, around one-third of the participants did not complete all three surveys and were therefore excluded from the analyses. It is possible that non-responders differed from responders, for example, in terms of workload. However, non-significant non-response analyses show that it is unlikely that this has biased our results. Future studies in larger samples with low attrition rate would enhance the generalisability of the findings.

Second, some questions in this study might generate a recall bias as they ask for past situations, for instance in the items measuring emotional workload asking for the existence of emotionally demanding past situations. We believe that this bias is limited, as we did not use retrospective questions in this study. Furthermore, research has shown that people are usually able to remember long-term periods or specific events, such as the COVID-19 pandemic. ${ }^{29}$

\section{Study implications}

This study contributes to the body of knowledge about the psychological impact of the COVID-19 pandemic on healthcare workers. It shows that the COVID-19 pandemic does not necessarily affect healthcare workers negatively; rather, it may also result in positive outcomes (ie, increasing employability). As physicians work experiences are dynamic, a longitudinal approach is necessary to capture the dynamics of a pandemic on physicians work experiences. Furthermore, this study is valuable to practice as the healthcare system's ability to cope during an influenza pandemic will depend, to a large extent, on the number of healthcare workers, including physicians who are able and willing to work through the crisis. ${ }^{8}$ This study can inform global health actors that develop human resource strategies for dealing with the aftermath of the COVID-19 outbreak on healthcare workers. This study shows that physicians with surgical, medical and other specialties experience the COVID-19 pandemic differently. Therefore, tailor-made human resource strategies seem appropriate that pay attention to the specific needs of individual physicians.

\section{CONCLUSION}

This is the first study to provide evidence on the effects of the COVID-19 pandemic on physicians' employability and work experience, using a longitudinal approach with real-time data at three moments in time. We found evidence that physicians' employability significantly increased from the time prior to the pandemic to the period during the COVID-19 pandemic. Also, physicians experience a lower workload during the first peak of the COVID-19 pandemic compared with the time before the pandemic. At a later phase in the pandemic, their experiences of workload bounce back to initial levels. These results show that employability and work experiences vary over time and in different phases of the COVID-19 pandemic. Physicians further experience the most stress from the impact of COVID-19 on their work in general and from combining work and private life.

Contributors All authors conceptualised the research project, reviewed and provided comments and revisions. All authors read and approved the final manuscript. EHvL coordinated the study and gathered participants. EHvL analysed the data and drafted the manuscript. As such, EHvL is the guarantor of this work and takes responsibility for the integrity of the data and the accuracy of the data analysis. TT, ELJvR, J-WL and EK secured funding for the project.

Funding The authors have not declared a specific grant for this research from any funding agency in the public, commercial or not-for-profit sectors.

Competing interests None declared.

Patient and public involvement Patients and/or the public were involved in the design, or conduct, or reporting, or dissemination plans of this research. Refer to the Methods section for further details.

Patient consent for publication Not applicable.

Ethics approval The Ethical Committee of the University Medical Centre Utrecht confirmed that this study falls outside the scope of the Dutch Law on Medical Research (WMO) and therefore formal ethical approval was not required (METC 2019, 20/328).

Provenance and peer review Not commissioned; externally peer reviewed.

Data availability statement Data are available on reasonable request. Ethical restrictions related to participant confidentiality prohibit the authors from making the dataset publicly available. 
Open access This is an open access article distributed in accordance with the Creative Commons Attribution Non Commercial (CC BY-NC 4.0) license, which permits others to distribute, remix, adapt, build upon this work non-commercially, and license their derivative works on different terms, provided the original work is properly cited, appropriate credit is given, any changes made indicated, and the use is non-commercial. See: http://creativecommons.org/licenses/by-nc/4.0/.

ORCID iD

Evelien H van Leeuwen http://orcid.org/0000-0002-1239-3126

\section{REFERENCES}

1 Pappa S, Ntella V, Giannakas T, et al. Prevalence of depression, anxiety, and insomnia among healthcare workers during the COVID-19 pandemic: a systematic review and meta-analysis. Brain Behav Immun 2020;88:901-7.

2 Ripp J, Peccoralo L, Charney D. Attending to the emotional wellbeing of the health care workforce in a new York City health system during the Covid-19 pandemic. Acad Med 2020;64:1-4.

3 Smith $\mathrm{C}$. The structural vulnerability of healthcare workers during COVID-19: observations on the social context of risk and the equitable distribution of resources. Soc Sci Med 2020;258:113119.

4 Pfefferbaum B, North CS. Mental health and the Covid-19 pandemic. N Engl J Med 2020;383:510-2.

5 Cooch $\mathrm{N}$. The psychological impact of Covid-19 on physicians: lessons from previous outbreaks, 2020. Available: https://www. practiceupdate.com/content/the-psychological-impact-of-covid19-on-physicians-lessons-from-previous-outbreaks/100995/45? trendmd-shared $=0$ [Accessed 9 Jul 2020].

6 Fargen KM, Leslie-Mazwi TM, Klucznik RP, et al. The professional and personal impact of the coronavirus pandemic on US neurointerventional practices: a nationwide survey. J Neurointerv Surg 2020;12:927-31.

7 Lai J, Ma S, Wang Y, et al. Factors associated with mental health outcomes among health care workers exposed to coronavirus disease 2019. JAMA Netw Open 2020;3:e203976.

8 Ives J, Greenfield S, Parry JM, et al. Healthcare workers' attitudes to working during pandemic influenza: a qualitative study. BMC Public Health 2009;9:1-13.

9 Vindrola-Padros C, Andrews L, Dowrick A, et al. Perceptions and experiences of healthcare workers during the COVID-19 pandemic in the UK. BMJ Open 2020;10:e040503.

10 Imai $\mathrm{H}$, Matsuishi $\mathrm{K}$, Ito A, et al. Factors associated with motivation and hesitation to work among health professionals during a public crisis: a cross sectional study of hospital workers in Japan during the pandemic (H1N1) 2009. BMC Public Health 2010;10:1-8.

11 Liu X, Kakade M, Fuller CJ, et al. Depression after exposure to stressful events: lessons learned from the severe acute respiratory syndrome epidemic. Compr Psychiatry 2012;53:15-23.

12 Maunder RG, Lancee WJ, Balderson KE, et al. Longterm psychological and occupational effects of providing Hospital healthcare during SARS outbreak. Emerg Infect Dis 2006;12:1924-32.

13 Bakker AB, van Veldhoven M, Xanthopoulou D. Beyond the demandcontrol model. J Pers Psychol 2010;9:3-16.

14 Karasek RA. Job demands, job decision latitude, and mental strain: implications for job redesign. Adm Sci Q 1979;24:285-308.

15 de Lange AH, Taris TW, Kompier MAJ, et al. "The very best of the millennium": longitudinal research and the demand-control-(support) model. J Occup Health Psychol 2003;8:282-305.

16 De Cuyper N, Sulea C, Philippaers K, et al. Perceived employability and performance: moderation by felt job insecurity. Pers Rev 2014;43:536-52.

17 Kirves K, Kinnunen U, De Cuyper N, et al. Trajectories of perceived employability and their associations with well-being at work. J Pers Psychol 2014;13:46-57.

18 Akkermans J, Seibert SE, Mol ST. Tales of the unexpected: integrating career shocks in the contemporary careers literature. $S A$ $J$ Ind Psychol 2018;44:1-10.
19 Akkermans J, Richardson J, Kraimer ML. The Covid-19 crisis as a career shock: implications for careers and vocational behavior. $J$ Vocat Behav 2020;119:103434.

20 Wallace JE, Lemaire JB, Ghali WA. Physician wellness: a missing quality indicator. Lancet 2009;374:1714-21.

21 Maunder R. The experience of the 2003 SARS outbreak as a traumatic stress among frontline healthcare workers in Toronto: lessons learned. Philos Trans $R$ Soc Lond B Biol Sci 2004;359:1117-25.

22 Naushad VA, Bierens JJ, Nishan KP, et al. A systematic review of the impact of disaster on the mental health of medical responders. Prehosp Disaster Med 2019;34:632-43.

23 Wu Y, Wang J, Luo C, et al. A comparison of burnout frequency among oncology physicians and nurses working on the frontline and usual wards during the COVID-19 epidemic in Wuhan, China. J Pain Symptom Manage 2020;60:e60-5.

24 Tiete J, Guatteri M, Lachaux A, et al. Mental health outcomes in healthcare workers in COVID-19 and non-COVID-19 care units: a cross-sectional survey in Belgium. Front Psychol 2020;11:1-10.

25 Willan J, King AJ, Jeffery K, et al. Challenges for NHS hospitals during covid-19 epidemic. BMJ 2020;368:m1117.

26 Tan BY, Chew NW, Lee GK. Psychological impact of the Covid-19 pandemic on health care workers in Singapore. Ann Intern Med 2020:1-3

27 Chong M-Y, Wang W-C, Hsieh W-C, et al. Psychological impact of severe acute respiratory syndrome on health workers in a tertiary hospital. Br J Psychiatry 2004;185:127-33.

28 Preti E, Di Mattei V, Perego G, et al. The psychological impact of epidemic and pandemic outbreaks on healthcare workers: rapid review of the evidence. Curr Psychiatry Rep 2020;22:1-22.

29 Schwarz N. Retrospective and concurrent self-reports: The rationale for real-time data capture. In: Stone A, Shiffman SS, Atienza A, et al. eds. The science of real-time data capture: Self-reports in health research. New York: Oxford University Press, 2007: 11-26. https:// dornsife.usc.edu/assets/sites/780/docs/schwarz_retrospective_selfreports_mdc_2007.pdf

30 Van Leeuwen EH, Knies E, Van Rensen ELJ. Stimulating perceived ability and willingness to continue working and job crafting behaviour of physicians: an intervention study. Dutch HRM Network Conference, Tilburg, 2019.

31 RIVM. Current information about Covid-19, 2021. Available: https:// www.rivm.nl/en/coronavirus-covid-19/current-information

32 Blank JLT, Niaounakis TK. Productiviteitsontwikkelingen bij medisch specialisten: Resultaten en technische rapportage. Delft 2019.

33 Van Veldhoven M, Prins J, Van der Laken P. VBBA 2.0: update van de standaard voor vragenlijstonderzoek naar werk, welbevinden en prestaties. Enschede: Gildeprint, 2014

34 Morgeson FP, Humphrey SE. The work design questionnaire (WDQ): developing and validating a comprehensive measure for assessing job design and the nature of work. J Appl Psychol 2006;91:1321-39.

35 Demerouti E, Le Blanc PM, Bakker AB, et al. Present but sick: a three-wave study on job demands, presenteeism and burnout. Career Dev Int 2009;14:50-68.

36 Oude Hengel KM, Blatter BM, Geuskens GA, et al. Factors associated with the ability and willingness to continue working until the age of 65 in construction workers. Int Arch Occup Environ Health 2012;85:783-90.

37 Wanous JP, Reichers AE, Hudy MJ. Overall job satisfaction: how good are single-item measures? J Appl Psychol 1997;82:247-52.

38 Martins LL, Eddleston KA, Veiga JF. Moderators of the relationship between work-family conflict and career satisfaction. Acad Manag $J$ 2002;45:399-409.

39 Van Dooren W, Noordegraaf M. Staging science: Authoritativeness and fragility of models and measurement in the COVID-19 crisis. Public Adm Rev 2020;80:610-5.

40 Bernburg M, Vitzthum K, Groneberg DA, et al. Physicians' occupational stress, depressive symptoms and work ability in relation to their working environment: a cross-sectional study of differences among medical residents with various specialties working in German hospitals. BMJ Open 2016;6:e011369.

41 Fowler A, Abbott TEF, Pearse RM. Can we safely continue to offer surgical treatments during the COVID-19 pandemic? BMJ Qual Saf 2021;30:268-270. 